\title{
Association between depressive symptoms and psychosocial factors and perception of maternal self-efficacy in teenage mothers
}

\author{
Ma. Asunción Lara, ${ }^{1}$ Pamela Patiño, ${ }^{1}$ Laura Navarrete, ${ }^{1}$ Zaira Hernández, ${ }^{2}$ Lourdes Nieto ${ }^{1}$
}

\begin{abstract}
1 Dirección de Investigaciones Epidemiológicas y Psicosociales, Instituto Nacional de Psiquiatría Ramón de la Fuente Muñiz, Ciudad de México, México.

2 Departamento de Psiquiatría, Hospital Universitario Dr. José E. González, Universidad Autónoma de Nuevo León, Nuevo León, Monterrey, México.
\end{abstract}

\section{Correspondence:}

Ma. Asunción Lara

Dirección de Investigaciones Epidemiológicas y Psicosociales, Instituto Nacional de Psiquiatría Ramón de la Fuente Muñiz.

Calz. México-Xochimilco 101, Col. San Lorenzo Huipulco, Del. Tlalpan, C.P. 14370, Ciudad de México, México.

Phone: +52 (55) 41605170

Fax: +52 (55) 55133446

Email: laracan@imp.edu.mx

Received first version: November 30, 2016

Second version: May 10, 2017

Accepted: September 6, 2017

doi.10.17711/SM.0185-3325.2017.026

\begin{abstract}
Introduction. Teenage pregnancy is a national health priority. Having to deal with pregnancy during adolescence can cause the mother, at an already vulnerable age, to doubt her maternal capacity to cope with a challenge of this magnitude. The teenage mother's assessment of her maternal self-efficacy is associated with her performance, in other words, the way she relates and responds to the needs of her infant, which has major implications for the latter's development. Objective. To study the association between personal (depressive symptoms, self-esteem) and environmental characteristics (social support, partner satisfaction) and those of the infant (problems with infant care, the infants's temperament) and the perception of maternal self-efficacy (PME) in adolescent mothers. Method. Cross-sectional study. The following instruments were applied: Center for Epidemiologic Studies Depression Scale (CES-D), Post-partum Depression Predictors Inventory-Revised (PDPI-R), and Maternal Efficacy Questionnaire to 120 mothers under 20 during the first six months postpartum. Bivariate lineal regression and hierarchical linear regression analyses were used for the data analysis. Results. When adjusting for other variables, symptoms of depression and difficult infant temperament were associated with lower PME. Social support was only associated with increased PME in the bivariate analysis. Discussion and conclusion. These findings contribute to the limited literature on the subject and provide elements for designing strategies to improve adolescent mothers' PME to encourage behaviors that are more relevant and sensitive to infants' physical and emotional needs.
\end{abstract}

Keywords: Postpartum depression, maternal self-efficacy, adolescents, psychosocial factors.

\section{RESUMEN}

Introducción. El embarazo adolescente es una prioridad nacional para la salud. Enfrentar un embarazo durante la adolescencia puede hacer que la madre, a una edad de por sí vulnerable, dude de su capacidad materna ante un reto de esta magnitud. La valoración que hace de su eficacia materna se asocia con su desempeño, esto es, con la manera de relacionarse y responder a las necesidades de su infante, misma que tiene consecuencias determinantes en el desarrollo de éste. Objetivo. Estudiar la asociación entre características personales (síntomas depresivos, autoestima), ambientales (apoyo social, satisfacción con la pareja) y del infante (problemas con el cuidado del infante, temperamento infantil) con la percepción de eficacia materna (PEM) en madres adolescentes. Método. Estudio transversal. Se aplicaron: Escala de Depresión del Centro de Estudios Epidemiológicos (CES-D), Inventario de Predictores de Depresión Posparto Revisado (PDPI-R) y Cuestionario de Eficacia Materna a 120 madres menores de 20 años durante el primer semestre posparto. Para los análisis de datos se usaron regresiones lineales bivariadas y análisis de regresión lineal jerárquica. Resultados. Al ajustar por otras variables, los síntomas de depresión y el temperamento infantil difícil se asociaron con más baja PEM. El apoyo social se asoció con mayor PEM sólo en los análisis bivariados. Discusión y conclusión. Estos hallazgos contribuyen a la escasa literatura sobre el tema y proveen elementos para el diseño de estrategias que mejoren la PEM en madres adolescentes para favorecer conductas más pertinentes y sensibles ante las necesidades físicas y emocionales de los infantes.

Palabras clave: Depresión posparto, eficacia materna, adolescentes, factores psicosociales. 


\section{INTRODUCTION}

Teenage pregnancy is a national health priority. According to the Encuesta Nacional de Salud y Nutrición (National Health and Nutrition Survey) (Gutiérrez et al., 2012), 20.5\% of adolescents between 12 and 19 years of age have begun their sex lives, half of whom $(51.9 \%)$ have been pregnant at one time and $10.7 \%$ of whom were pregnant at the time of the interview; in 2011, 37 out of every 1,000 births were to adolescents.

A pregnancy during this period represents an adaptive challenge, since adolescence is already a stage of adjustment in all areas of development (DeVito, 2007), with repercussions for the health and maturation process of the mother and infant. In 2013, of the total hospital discharges of women ages 15 to $19,83.9 \%$ were due to obstetric causes, including miscarriage and complications during pregnancy, childbirth, or the puerperium (Instituto Nacional de Estadística y Geografía, INEGI, 2015). Children of adolescent mothers are at an increased risk of mortality, morbidity, cognitive impairment, child abuse, neglect, social-emotional deficit, and academic difficulty and failure (Baldwin \& Cain, 1980; Shapiro \& Mangelsdorf, 1994). Coping with pregnancy in adolescence can cause the young mother, who is already vulnerable, to doubt her abilities in the face of a challenge of this magnitude. Moreover, young women tend to perceive their infants as more difficult and to have unrealistic expectations about childraising (Brooks-Gunn \& Furstenberg, 1986; Brooks-Gunn \& Chase-Lansdale, 1995).

Self-efficacy is defined as people's beliefs about their ability to perform a task and determines how they feel, think, and are motivated to carry out an action. People with high confidence in their abilities tend to approach difficult tasks as a challenge, do not avoid them, and, when faced with failure, regard it as a lack of experience and knowledge rather than something impossible to overcome, which reduces the stress and the risk of depression, while at the same time reinforces their concept of efficacy (Bandura, 1994).

Perception of maternal self-efficacy (PME) refers to the mother's beliefs about her ability to perform her maternal role (Teti \& Gelfand, 1991). The literature on the subject uses several terms to refer to the PME: self-perception of maternal competence and perception of the ability to provide maternal care. Studying these perceptions is important since they relate to parenting behaviors. In other words, parents who feel effective are more competent as parents (Kendall \& Bloomfield, 2005) and better able to cope with problems with their infants (Bouma \& Schweitzer, 1990; Hastings \& Brown, 2002). Conversely, mothers who feel less efficient, for example in soothing their babies when they cry, will make fewer attempts to calm them down and give up quickly if they do not respond to their efforts (Coleman \& Karraker, 1998). Like- wise, they will attribute the failure to themselves, which will create negative feelings and reinforce their low PME (Cutrona \& Troutman, 1986).

Given the importance of the latter, we have tried to determine the personal, environmental, and infant-related factors that encourage or diminish the perception of the mother's self-efficacy.

In this regard, postnatal depression is one of the main personal factors impacting PME. In a multi-ethnic sample, Cox et al. (2008) observed that depression symptoms diminished adolescents' perception of their ability to care for the infant at two weeks after birth, a result similar to that observed in adult women (Knoche, Givens, \& Sheridan, 2007; Navarro, Navarrete, \& Lara, 2011; Leahy-Warren \& McCarthy, 2011; Le \& Lambert, 2008).

Most adolescent mothers live with their families (Instituto Nacional de Estadística y Geografía, INEGI, 2015; Álvarez-Nieto, Pastor-Moreno, Linares-Abad, Serrano-Martos, \& Rodríguez-Olalla, 2014), so the support they receive from them is crucial. This support is critical and decisive in the adolescent's positive adjustment to motherhood (DeVito, 2007; Clemmens, 2001). It has been observed that the girl's mother is the most important source of support in the first postnatal weeks, emotional support being most closely associated with better PME, whereas practical support -assuming some of the adolescent's responsibilities- reduces PME (DeVito, 2007). However, other studies do not find a link between family support and PME, although they do find one between support from the infant's father and perceived maternal self-efficacy (Shapiro \& Mangelsdorf, 1994).

In adult mothers, an infant's difficult temperament also negatively impacts PME (Cutrona \& Troutman, 1986; Azmoude, Jafarnejade, \& Mazlom, 2015). An infant who cries a lot, is not easy to soothe, or is irritable makes care more difficult and may result in both the father and mother developing negative attitudes and decreasing their sense of competence (Coleman \& Karraker, 1998; Lipscomb et al., 2011). When the mother's attempts to calm and soothe her baby are successful, this increases the likelihood she will feel effective (Coleman \& Karraker, 1998).

Other personal and environmental factors associated with low PME in adolescent mothers, which have been less studied, are lower age and educational attainment (DeVito, 2007) and, in adults, not having a partner (Navarro et al., 2011), experiencing stressful events (Navarro et al., 2011; Farkas \& Valdés, 2010), marital status, maternal stress, and anxiety (Leahy-Warren \& McCarthy, 2011).

Although adolescent mothers and their infants are an extremely vulnerable population, their mental health and aspects related to motherhood have scarcely been studied, particularly in Latin America. As mentioned, there is evidence that mothers' assessment of their maternal capacity is associated with their performance in this role, in other words, with the way they relate to and respond to the infants' 
needs, which has decisive consequences on their development. Based on these findings, it is important to determine the aspects that affect the perception of maternal self-efficacy in this population. The purpose of this study was to study the association between personal (depressive symptoms and self-esteem), environmental (social support and satisfaction with one's partner, among others), infant-related characteristics (temperament), and PME in adolescent mothers. This information will contribute to increasing the scant knowledge about motherhood in adolescents, and to incorporating it into the development of strategies to improve the feeling of maternal competence of this population, which will encourage healthy sensitive maternal behaviors in response to infants' physical and emotional needs.

\section{METHOD}

\section{Design}

Cross-sectional correlational-descriptive research.

\section{Participants}

A non-probabilistic sample of 120 adolescents attending immunization, screening, and general medical services was recruited at two health centers in Mexico City: one in Iztapalapa and another in Xochimilco. Sample size was determined through the program G Power: Statistical Power Analysis, designed by Düsseldorf University (Faul, Erdfelder, Buchner, \& Lang, 2009), for a multivariate linear analysis, with an effect size of $\mathrm{f} 2$ of .35 (suggested in Cárdenas \& Arancibia, 2014), a statistical power of .95, and a level of significance of .05 , for 15 predictors.

The population attended by these centers is mostly low income without social security coverage. The inclusion criteria were: being up to 19 years of age and within the first six months postpartum. The exclusion criteria were: that the mother had had health problems during childbirth or postpartum that caused her to stay in hospital for more than a week or that the newborn had had very low birth weight $(<$ $1.5 \mathrm{~kg}$ ), been born before the age of 32 weeks gestation or experienced any health complication that required hospitalization or specialized medical care.

\section{Instruments}

The instrument was applied through an interview by trained personnel and included four areas.

1. Sociodemographic and infant care (age, educational attainment, occupation, people with whom they live, who taught them how to take care of the baby, whether they receive help with looking after the infant, and who cares for the infant when s/he is awake).
2. The Maternal Efficacy Questionnaire (Teti and Gelfand, 1991) includes 10 questions that explore how effective the mother considers herself to be in various infant care settings. Answers are given on a Likert scale $(1=$ not good, $4=$ very good). The total score of the scale ranged from 10 to 40. In the adult Mexican population, it proved to have adequate reliability at six weeks $(\alpha=.81)$ and at between four and six months postpartum $(\alpha=.78)(\mathrm{Na}-$ varro et al., 2011); it was also adequate in the present study: $\alpha=.77$. In the absence of cut-off points, the mean, minus one standard deviation, was used as the criterion for low PME, which yielded a value of 26.

3. Risk factors associated with PME were measured using the Revised Postoperative Depression Inventory (PDPI-R) (Records, Rice, \& Beck, 2007). Typically, the instrument is used to evaluate risk factors for postpartum depression (PPD). It was chosen for this study since a single questionnaire includes the main variables of interest. The PDPI-R consists of 13 subscales; some with several items. It has been validated in the Mexican population (Ibarra-Yruegas, Lara, Navarrete, Nieto, \& Kawas-Valle, 2016).

The PDPI-R sub-scales are: marital status (1 item), socioeconomic status (1 item), self-esteem (3 items), prenatal depression (1 item), prenatal anxiety (1 item), unplanned/unwanted pregnancy (3 items), history of depression (1 item), social support (12 items), marital/ partner satisfaction (3 items), life stress ( 7 items), child care stress (3 items), infant's temperament (3 items) and maternity blues ( 1 item). The subscale on socioeconomic status was not included in the analysis because it proved to have little validity (Ibarra-Yruegas et al., 2016), although age was included within the risk factors as an extra subscale. The items are answered as follows: yes (1) (poses a risk) or no (0) (does not pose a risk). In the case of subscales with several items, the value of the subscale is the sum of each one.

4. Depression symptoms were assessed using the Center for Epidemiological Studies (CES-D) Depression Scale (Radloff, 1977). This scale consists of 20 questions regarding the symptoms experienced during the past week, which are answered on a range of 0 (seldom or never) to 3 (most of the time). A score $\geq 16$ indicates a high risk of depression. The scale was validated in Mexican adolescents $(\alpha=.93)$ (González-Forteza, Jiménez-Tapia, Ramos-Lira, \& Wagner, 2008). The final CES-D score was analyzed together with the risk factors (PDPI-R) as an additional subscale.

\section{Procedure}

In order to encourage the adolescents to participate in the study, the objectives were explained to them. Those who were interested and met the selection criteria had the letter 
of informed consent read to them, which they were asked to sign. According to Guideline 14 of the Consejo de Organizaciones Internacionales de las Ciencias Médicas (CIOMS [Council for International Organizations of Medical Sciences], 2002), adolescent mothers are considered to be emancipated persons, since they take care of a third party, as a result of which parents' or guardians' consent is not required. In some cases, the parents who accompanied them for consultation were told about the interviews at the adolescents' request. Subsequently, the interview was conducted in a secluded part of the waiting room. The research protocol was approved by the Institutional Review Board (IRB) of the Instituto Nacional de Psiquiatría Ramón de la Fuente Muñiz.

\section{Data analysis}

In order to evaluate the association between psychosocial variables and PME (with an interval measurement level), bivariate linear regressions were carried out, which included both the total values of the subscales mentioned in the instruments section and the items comprising them, and the age and depression variables (CES-D). Second, in order to determine the joint effect of the risk factors, a three-step hierarchical linear regression was performed. All the subscales were introduced regardless of whether they were significant in the bivariate analyses. Items in the subscales were not included separately in order to avoid collinearity. Personal variables were included in the first one, environmental variables in the second, and the infants' characteristics in the third. At each stage, the following are reported: the standardized coefficients of each variable, the value of $F$, the adjusted $R^{2}$, and the changes in these values. There were missing values. All the analyses were performed using the IBM SPSS 22 program.

\section{RESULTS}

\section{Sample characteristics}

The mothers had a mean age of $17.51( \pm 1.3)$ years and the infants a mean age of $12.82( \pm 6.64)$ weeks. They had completed or were attending middle school $(50.8 \%)$ or high school (39.1\%) and lived with their partners (55.0\%), either just with their partners $(24.2 \%)$, with her parents $(20.8 \%)$ or his parents $(19.2 \%)$ (Table 1).

The majority were homemakers and looked after their babies $(70.0 \%)$, while $28.8 \%$ studied or worked. This was their first pregnancy $(81.7 \%) ; 78.3 \%$ received some instruction regarding the care of the baby, mainly from their mothers or a relative $(74.5 \%) ; 74.2 \%$ received support for the care of the infant, either from their mothers or a relative $(75.9 \%)$; $39.2 \%$ cared for the baby while s/he was awake and in $22.5 \%$ of all cases, the partner also participated in this care.
The mean in the maternal self-efficacy scale was 30.22 ( \pm 4.38) and $20.8 \%$ were classified as having low PME ( $\geq$ 26). The mean of depression symptoms was $13.8( \pm 9.27)$, while $33.3 \%$ showed depressive symptoms (CES-D $\geq 16$ ).

Table 1

Characteristics of adolescents $(N=120)$

\begin{tabular}{|c|c|c|}
\hline & $f$ & $\%$ \\
\hline \multicolumn{3}{|l|}{ Age } \\
\hline $15-17$ & 54 & 45.0 \\
\hline $18-19$ & 66 & 55.0 \\
\hline \multicolumn{3}{|l|}{ Educational attainment ${ }^{1}$} \\
\hline Elementary school & 7 & 5.9 \\
\hline Middle school & 61 & 50.8 \\
\hline High school & 47 & 39.2 \\
\hline University & 5 & 4.2 \\
\hline \multicolumn{3}{|l|}{ Marital status } \\
\hline Single & 46 & 35.8 \\
\hline Married & 11 & 9.2 \\
\hline Living with partner & 66 & 55.0 \\
\hline \multicolumn{3}{|l|}{ Occupation } \\
\hline Home and baby care & 84 & 70.0 \\
\hline Studies and takes care of baby & 15 & 12.5 \\
\hline Paid work and takes care of baby & 19 & 15.8 \\
\hline Studies, works, and takes care of baby & 2 & 1.7 \\
\hline \multicolumn{3}{|l|}{ First pregnancy } \\
\hline Yes & 98 & 81.7 \\
\hline \multicolumn{3}{|l|}{ People she lives with } \\
\hline Her parents and partner & 25 & 20.8 \\
\hline Her parents & 42 & 35.0 \\
\hline Partners' family & 23 & 19.2 \\
\hline Partner & 29 & 24.2 \\
\hline Alone with her children & 1 & .8 \\
\hline \multicolumn{3}{|c|}{ Someone taught her how to take care of her baby } \\
\hline Yes & 94 & 78.3 \\
\hline \multicolumn{3}{|l|}{ Who taught her } \\
\hline Her family ${ }^{2}$ & 70 & 74.5 \\
\hline Partners' relatives & 11 & 11.7 \\
\hline Both families & 8 & 8.5 \\
\hline Friends or acquaintances & 1 & 1.1 \\
\hline Professional healthcare & 4 & 4.2 \\
\hline Gets help with baby care & 89 & 74.2 \\
\hline Yes & & \\
\hline \multicolumn{3}{|l|}{ Who she gets help from } \\
\hline Her family ${ }^{3}$ & 66 & 75.9 \\
\hline Partner's family & 14 & 16.1 \\
\hline Both families & 7 & 8.0 \\
\hline \multicolumn{3}{|c|}{ Who looks after the baby when s/he is awake? } \\
\hline Her & 47 & 39.2 \\
\hline She and her partner & 27 & 22.5 \\
\hline She and her mother & 15 & 12.5 \\
\hline She and her family & 26 & 21.7 \\
\hline She and the baby's father's family & 5 & 4.2 \\
\hline
\end{tabular}

Note: ${ }^{1}$ It includes those who have either completed or partially completed these levels; ${ }^{2}$ The mother, grandmother and sisters, mainly, but also aunts, cousins, and other women who have already had children; ${ }^{3}$ Mainly, the mother and grandmother and other women. 
Table 2

Mean and percentages of risk factors (PDPI-R) and their association with Maternal Self-Efficacy Perception

$\beta$

Personal
Age
Unplanned/unwanted preg
Married or living together
Postpartum depression (CES
Prenatal depression
Maternity blues
History of depression
Prenatal anxiety
Self-esteem
Feels good about herself
Feels worthy
Has qualities
Development
Social support

Emotional support from partner

Trusts partner

Counts on partner

Practical support from partner

Emotional support from family

Trust family

Count on family

Practical Support from Family

Emotional support from friends

Trust friends

Count on friends

Practical support from friends

Marital / Partner satisfaction

Satisfied with couple

relationship

Current problems with partner

Things are going well with her partner

Stressful events

Financial problems

Partner problems

Death of a family member

Unemployed

Serious illness of a relative

Moving house

Change job/leave school

Infant-related problems

Childcare stress

Baby experiences health problems

Problems feeding baby

Problems getting the baby to go to sleep

Infant temperament

Irritable baby

Baby cries a lot

Difficulty soothing baby

$\begin{array}{ccc}\mathrm{M}=17.5 & \mathrm{SD}=1.3 & .12 \\ \mathrm{M}=1.3 & \mathrm{SD}=.8 & -.06 \\ \text { Yes } & \mathrm{No} & \\ 64.2 \% & 35.8 \% & -.04 \\ 33.3 \% & 66.7 \% & -.28^{* *} \\ 51.7 \% & 48.3 \% & -.03 \\ 39.2 \% & 60.8 \% & -.01 \\ 30.0 \% & 70.0 \% & .01 \\ 51.7 \% & 48.3 \% & .07 \\ \mathrm{M}=.1 & \mathrm{SD}=.4 & -.03 \\ \mathrm{Yes} & \mathrm{No} & \\ 92.5 \% & 7.5 \% & .07 \\ 97.5 \% & 2.5 \% & -.02 \\ 90.8 \% & 9.2 \% & -.11 \\ & & \\ \mathrm{M}=3.9 & \mathrm{SD}=2.4 & -.23^{* *} \\ \mathrm{Yes} & \mathrm{No} & \\ 69.2 \% & 30.8 \% & -.07 \\ 70.0 \% & 30.0 \% & -.06 \\ 75.8 \% & 24.2 \% & -.06 \\ 69.2 \% & 30.8 \% & -.02 \\ 85.0 \% & 15.0 \% & -.10 \\ 82.5 \% & 17.5 \% & -.11 \\ 90.8 \% & 9.2 \% & -.18 \\ 80.8 \% & 19.2 \% & -.18^{*} \\ 54.2 \% & 45.8 \% & -.18^{*} \\ 50.0 \% & 50.0 \% & -.16^{*} \\ 55.8 \% & 44.2 \% & -.15^{*} \\ 26.7 \% & 73.3 \% & -.08 \\ \mathrm{M}=.8 & \mathrm{SD}=1.2 & -.10 \\ \mathrm{Yes} & \mathrm{No} & \\ & & \\ 73.3 \% & 26.7 \% & -.08 \\ 35.0 \% & 65.0 \% & -.13 \\ 73.3 \% & 26.7 \% & -.03 \\ \mathrm{M}=1.9 & \mathrm{SD}=1.3 & .05 \\ \mathrm{Yes} & \mathrm{No} & \\ 42.5 \% & 57.5 \% & -.04 \\ 35.0 \% & 65.0 \% & -.10 \\ 17.5 \% & 82.5 \% & .06 \\ 27.5 \% & 72.5 \% & .14^{*} \\ 24.2 \% & 75.8 \% & .05 \\ 20.8 \% & 79.2 \% & .04 \\ 25.0 \% & 75.0 \% & .00\end{array}$

$\mathrm{M}=.5 \quad \mathrm{SD}=.6 \quad-.15^{*}$

Yes No

$19.2 \% \quad 80.8 \% \quad-.08$

$11.7 \% \quad 88.3 \% \quad-.05$

$19.2 \% \quad 80.8 \% \quad-.11$

$\mathrm{M}=.4 \quad \mathrm{SD}=.8 \quad-.28^{* *}$

Yes No

$7.5 \% \quad 92.5 \% \quad-.19^{*}$

$17.5 \% \quad 82.5 \% \quad-.25^{*}$
$17.5 \% \quad 82.5 \% \quad-.21^{*}$

Note: Socioeconomic Level scale omitted; ${ }^{*}<.05 ;{ }^{* *}<.01$.

Association between psychosocial factors and
PME

Table 2 shows the frequencies and standardized coefficients of bivariate linear regression between each of the factors of the PDPI, age and CES-D and the PME, of both the complete scales, and each of the questions comprising those scales. Subscales are grouped by area.

Of the personal variables, only depression (CES-D) was significant $(\beta=-.28 ; p=.00)$; of the environmental ones, social support was significant $(\beta=-.23 ; p=.00)$, and of this subscale, practical support from the family $(\beta=-.18$; $p=.02)$, emotional support from friendships $(\beta=-.18 ; p=$ .03 ), relying on friendships ( $\beta=-.16 ; p=.04$ ) and having friendships $(\beta=-.15 ; p=.04$ ) were significantly related to PME. Of the infant-related variables, problems with infant care (global) $(\beta=-.15 ; p=.04)$ and infant temperament (global) $(\beta=-.28 ; p=.00)$ were significant, and from this scale, having an irritable baby $(\beta=-.19 ; p=.02)$, a baby cries a lot $(\beta=-.21 ; p=.02)$ and having difficulty soothing $\operatorname{him}(\beta=-.25 ; p=.03)$, were significantly related to PME.

The hierarchical linear regression analysis of the effect of personal, environmental, and infant characteristics, introduced in that order, on PEM (Table 3), showed, in step 1, that depressive symptomatology was significantly associated with low PME $\left(\beta=-.30 ; r^{2}=.05 ; f=1.56\right)$, while social support was no longer significant. In step 3 , both depression symptoms $(\beta=-.33)$ and having an infant with a difficult temperament $(\beta=-.29)$ were significantly associated with low PME $\left(r^{2}=.15 ; f=2.50\right)$. This last step was the one that best explained lower PME (change in $F=7.05$ ), accounting for $15 \%$ of the variance. Finally, the $f^{2}$ of the hierarchical linear regression model was calculated from $\mathrm{R}^{2}$. A value of .18 was obtained, which is equivalent to a mean effect (Cárdenas \& Arancibia, 2014). This indicates that the effect of the variables incorporated into the model is appropiate.

\section{DISCUSSION AND CONCLUSION}

The objective of the study was to evaluate the association between various psychosocial factors and the perception of maternal self-efficacy in adolescent mothers. Firstly, $20.8 \%$ of mothers obtained low PME scores, a significant percentage given its implications for infant care. However, we do not have comparative parameters of similar populations, which makes it difficult to see this result in context. In this respect, Teti and Gelfand (1991), based on Bandura's formulation (1989), ask whether low PME is related to the mother's lack of confidence in herself or to a lack of knowledge about how to look after her baby. The data from this study only show that a fifth of the mothers interviewed said that no one had taught them how to look after their newborn babies. While future studies should explore 
Table 3

Hierarchical Linear Regression of Factors Associated with Perception of Maternal Self-Efficacy

\begin{tabular}{|c|c|c|c|c|c|}
\hline & $\mathrm{R}^{2}$ & $\Delta \mathrm{R}^{2}$ & $\mathrm{~F}$ & $\beta$ & EE \\
\hline Step 1. Personal factors & .05 & .00 & 1.72 & & \\
\hline Marital status & & & & -.01 & .98 \\
\hline Age & & & & .07 & .68 \\
\hline Unplanned/unwanted pregnancy & & & & -.02 & .52 \\
\hline \multicolumn{6}{|l|}{ CES-D Depression symptoms } \\
\hline Prenatal depression & & & & .11 & .87 \\
\hline Maternity blues & & & & .05 & .84 \\
\hline History of depression & & & & .05 & .90 \\
\hline Prenatal anxiety & & & & .10 & .82 \\
\hline Self-esteem & & & & .07 & .99 \\
\hline Step 2. Environmental factors & .05 & .00 & 1.56 & & \\
\hline Marital Status & & & & -.07 & 1.11 \\
\hline Age & & & & .08 & .61 \\
\hline Unplanned/unwanted pr & & & & -.04 & .52 \\
\hline CES-D depression symp & & & & $-.30^{* *}$ & .05 \\
\hline Prenatal depression & & & & .11 & .89 \\
\hline Maternity blues & & & & .05 & .85 \\
\hline History of depression & & & & .02 & .93 \\
\hline Prenatal & & & & .09 & .83 \\
\hline Self-esteem & & & & .04 & 1.00 \\
\hline Social su & & & & -.16 & .18 \\
\hline ner satisfaction & & & & -.05 & .49 \\
\hline Stressful events & & & & .08 & .34 \\
\hline Step 3. Factors related to the infant & .15 & .10 & $2.50^{* *}$ & & \\
\hline Marital Status & & & & -.01 & 1.10 \\
\hline Age & & & & .05 & .58 \\
\hline Unplanned/unwanted pr & & & & -.03 & .49 \\
\hline CES-D depres & & & & $-.33^{* *}$ & .05 \\
\hline Prenatal depression & & & & .09 & .84 \\
\hline Mater & & & & .12 & .82 \\
\hline of depression & & & & .07 & .89 \\
\hline Prenatal anxiety & & & & .13 & .79 \\
\hline Self-esteem & & & & .09 & .96 \\
\hline Social support & & & & -.08 & .17 \\
\hline Satisfaction with partner & & & & -.02 & .47 \\
\hline Stressful events & & & & .11 & .32 \\
\hline Problems with taking care of infant & & & & -.16 & .68 \\
\hline Infant temperament & & & & $-.29^{\star \star}$ & .49 \\
\hline
\end{tabular}

Note: ${ }^{* *} p<.01$; EE: $\mathrm{R}^{2}=$ Variance explained by the model; $\Delta \mathrm{R}^{2}=$ Change in variance explained by the model; $F=$ ANOVA value; $\beta=$ Standardized coefficients; $\mathrm{EE}=$ Standard error.

aspects associated with low PME in this population, based on Bandura's (1987) theory of social learning, perception of maternal competence could be increased by: giving the mother feedback when her mothering behaviors are appropriate, providing her with useful information, offering her effective maternal models, and developing her mothering skills (Bandura, 1987).

Consistent with the literature on adolescent (Cox et al., 2008) and adult mothers (Knoche et al., 2007; Navarro et al., 2011; Leahy-Warren \& McCarthy, 2011; Le \& Lambert, 2008) postnatal depression symptoms were the variable most strongly associated with low PME. In the hierarchical regression analysis, depressive symptomatology remained significant in each of the steps into which this variable was introduced, showing its degree of importance for PME regardless of the presence of other factors. Conversely, a history of depression, prenatal depression, and maternity blues failed to show any influence on the variable in question. This suggests that the depressive symptoms present are those that affect the perception of maternal self-efficacy, since, as suggested by Bandura (1989), they act as a sort of cognitive filter, contributing to the tendency to remember more failures and to see interpersonal events in a pessimistic way, while decreasing maternal confidence and gratification (Panzarine, Slater, \& Sharps, 1995). In addition, they affect the mother's warmth, verbalization, sensitivity, and responsiveness to the infant's needs (Lanzi, Bert, \& Jacobs, 2009). This finding becomes more relevant in light of the fact that $33.3 \%$ of the sample displayed these symptoms and that there is evidence that levels of depressive symptomatology increase throughout the postnatal period, becoming higher in the postpartum year (Lara et al., 2012). This increase appears to stem from difficulties in dealing with older infants, who are therefore more active and demanding and with the fact that many mothers do not go back to school or have partners.

Only the bivariate analysis showed that adolescents who lacked social support (total) did not have lower PME, a result that is in line with previous studies of adults (Razurel, Kaiser, Antonietti, Epiney, \& Sellenet, 2017). However, in the hierarchical analysis, once depressive symptomatology was introduced into the model, it became more important and social support was no longer significant. Other studies describe a similar phenomenon, in the sense that social support only impacts PME indirectly by reducing depression symptoms (Cox et al., 2008).

Although the total social support variable was not significant in the linear regression analysis, it is important to highlight some of the results of the bivariate analyses. Not having practical support from the family, mainly from the adolescent's mother and family, was related to their perception of themselves as less effective mothers. This result differs from that of other studies, which show that emotional support is more important than practical support (DeVito, 2007). The importance of practical support in this study could be linked to the mothers' low socioeconomic status, meaning that this type of support may be crucial to the infant's survival.

At the same time, emotional support from friends, as well as being able to count on and trust them, is crucial to PME. In this respect, Shapiro and Mangelsdorf (1994) consider that the significance of peers can be understood from the context of adolescence, since one of the main changes at this stage is the formation of new relationships with peers and moving away from the family environment.

Problems with caring for one's baby and the latter's difficult temperament, overall and in particular, describing the infant as irritable and crying a lot and having difficulty 
soothing her or him, had a significant effect on making mothers feel less effective. Hierarchical analysis showed that a difficult temperament remained a significant variable when other variables were controlled for, together with depressive symptoms. As happens with adults (Cutrona \& Troutman, 1986; Azmoude et al., 2015; Lipscomb et al., 2011), adolescents are affected by the infant's temperament. In other words, when attempts to soothe the infant continuously fail, they are more likely to feel less effective as mothers (Coleman \& Karraker, 1998). An additional pathway whereby the infant's difficult temperament affects PME is its association with depressive symptomatology, which was also a factor that was present, according to the analysis model.

In short, the factors that significantly affect the perception of maternal self-efficacy in adolescent mothers are the baby's difficult temperament and the symptoms of postpartum depression. The following elements help to explain this relationship. Adolescent mothers tend to perceive their infants as more difficult than adult mothers do (Shapiro \& Mangelsdorf, 1994; Brooks-Gunn \& Furstenberg, 1986), but they will perceive them as extremely problematic when they have a difficult temperament, in other words, hard to soothe, highly reactive to environmental stimuli, and unable to regulate their emotions. In this case, the mother is required to be more sensitive and persevering, so that the infant learns to regulate her or his emotions. However, this type of response will be hampered by the presence of postpartum depression symptoms. The combination of both factors will undermine their confidence in their mothering skills (Lanzi et al., 2009), while at the same time, less confidence in their qualities, will make it more difficult to respond adequately in order to soothe the baby (Coleman \& Karraker, 1998). This vicious circle can lead to infant neglect and abuse (Baldwin \& Cain, 1980; Shapiro \& Mangelsdorf, 1994).

Social support was a significant factor in terms of better PME, but this was probably because of its effect on depressive symptomatology. These findings are consistent with those of other studies (Cutrona \& Troutman, 1986; Cox et al., 2008; Knoche et al., 2007; Navarro et al., 2011; Leahy-Warren \& McCarthy, 2011; Le \& Lambert, 2008; Álvarez-Nieto et al., 2014; Clemmens, 2001; Azmoude et al., 2015; Lipscomb et al., 2011).

Although these conclusions are based on a relevant methodology, it is important to note that in the multivariate model, the significant variables explain only $15 \%$ of the variance, indicating that there are other factors involved in PME, possibly related to the population's socioeconomic level (Pereira et al., 2011). This suggests the need for future studies to include the way the context of the scarce resources that characterize the population attending these health centers may also be related to the perception of maternal self-efficacy in young mothers.

One should also consider the fact that, since it is a cross-sectional design, it is only possible to speak of associa- tions between variables, however much their causal relationship is supported by the literature, rather than of predictions, which could only be concluded from a longitudinal study. Regarding the generalizability of the findings, it should be noted, on the one hand, that the sociodemographic composition of the sample is similar to that described by Instituto Nacional de Estadística y Geografía (INEGI, 2015) and by the Consejo de Evaluación del Desarrollo Social del Distrito Federal (Martínez \& Quintino, 2016) for the population of adolescent mothers. However, the fact that the sample is not probabilistic and was selected at health centers when mothers took their infants in for their vaccinations may limit the generalizability of the data. In this respect, we do not know whether those who did not take their babies in for their vaccinations may have had different characteristics from the mothers selected, such as not having flexible time or schedules or being less involved in the activities related to their babies' health care.

The study's greatest contribution is to address one of the many problems arising from adolescent pregnancy, which is considered a national health priority. Among the suggestions for health policies in this population, the data from this and other studies (Lara et al., 2012; DeCastro, Hinojosa-Ayala, \& Hernandez, 2011) point to the need to detect depressive symptomatology in prenatal care services. There is evidence of the maternal self-efficacy of psycho-education strategies to prevent PPD in adult mothers, which could be used as an example to begin designing programs for adolescents regarding depression symptoms, strengthening the social support network, and educating young women about child development and caring for difficult babies (Lara, Navarro, \& Navarrete, 2010). It is also necessary to increase the involvement of service providers in the area of perinatal care in these activities (Baginsky, 2008), since, as seen in this study, only $4.2 \%$ participate in these tasks, according to the teenagers' answers.

Implementing measures such as these will not only influence the mother's effectiveness, but potentially also the development and mental health of infants who, as mentioned earlier, are at an increased risk of cognitive impairment and social-emotional deficit (Baldwin \& Cain, 1980; Barry, Dunlap, Cotten, Lochman, \& Wells, 2005).

\section{Funding}

None.

\section{Conflict of interest}

The authors declare they have no conflict of interest.

\section{Acknowledgements}

Thanks are due to Feliciano Bartolo Solís, Directorate of Health Care, Public Health Services of Mexico City and the team: Gloria Ivette Sánchez García, Arianna Elisa Zavala Puebla and Beatriz Mendoza Arce. 


\section{REFERENCES}

Álvarez-Nieto, C., Pastor-Moreno, G., Linares-Abad, M., Serrano-Martos, J., \& Rodríguez-Olalla, L. (2014). Maternidad temprana: percepciones e implicaciones de las madres de las adolescentes. Matronas Profesión, 15(3), 88-94.

Azmoude, E., Jafarnejade, F., \& Mazlom, S. R. (2015). The predictors for maternal self-efficacy in early parenthood. Journal of Midwifery and Reproductive Health, 3(2), 368-376. doi: 10.22038/JMRH.2015.4050

Baldwin, W., \& Cain, V. S. (1980). The children of teenage parents. Family Planning Perspectives, 12(1), 34-43.

Bandura, A. (1987). Pensamiento y acción: Fundamentos sociales. Barcelona: Martínez Roca.

Bandura, A. (1989). Regulation of cognitive processes through perceived self-efficacy. Developmental Psychology, 25(5), 729-735.

Bandura, A. (1994). Self-efficacy. In: V. S. Ramachaudran, (Ed.), Encyclopedia of human behavior (Vol. 4, pp. 71-81). New York: Academic Press.

Baginsky, B. A. (2008). Prevention of depression in postpartum adolescents. Journal of Student Nursing Research, 2(1), 10-14.

Barry, T. D., Dunlap, S. T., Cotten, S. J., Lochman, J. E., \& Wells, K. C. (2005). The influence of maternal stress and distress on disruptive behavior problems in boys. Journal of the American Academy of Child and Adolescent Psychiatry, 44(3), 265-273. doi: 10.1097/00004583-200503000-00011

Bouma, R., \& Schweitzer, R. (1990). The impact of chronic childhood illness on family stress: A comparison between autism and cystic fibrosis. Journal of Clinical Psychology, 46(6), 722-730.

Brooks-Gunn, J., \& Furstenberg, F. F. (1986). The children of adolescent mothers: Physical, academic, and psychological outcomes. Developmental Review, 6(3), 224-251. doi:10.1016/0273-2297(86)90013-4

Brooks-Gunn, J., Chase-Lansdale, P. L. (1995). Adolescent parenthood. In: M. H. Bornstein (Ed.), Handbook of parenting, Vol. 3. Status and social conditions of parenting (pp. 113-149). Hillsdale, NJ: Lawrence Erlbaum Associates.

Cárdenas, M., \& Arancibia, H. (2014). Potencia estadística y cálculo del tamaño del efecto en $\mathrm{G}^{*}$ Power: complementos a las pruebas de significación estadística y su aplicación en psicología. Salud \& Sociedad, 5(2), 210-224.

Clemmens, D. (2001). The relationship between social support and adolescent mothers' interactions with their infants: A meta-analysis. Journal of Obstetric, Gynecologic, \& Neonatal Nursing, 30(4), 410-420. doi: 10.1111/j.1552-6909.2001. tb01560.x

Coleman, P. K., \& Karraker, K. H. (1998). Self-efficacy and parenting quality: Findings and future applications. Developmental Review, 18(1), 47-85. doi:10.1006/ drev.1997.0448

Consejo de Organizaciones Internacionales de las Ciencias Médicas. (2002). Pautas Éticas Internacionales para la Investigación Biomédica en Seres Humanos: Programa regional del Bioética OPS-/OMS. Retrieved from: https://cioms.ch/ shop/product/pautas-eticas-internacionales-para-la-investigacion-biomedica-en-seres-humanos

Cox, J. E., Buman, M., Valenzuela, J., Joseph, N. P., Mitchell, A., \& Woods, E. R. (2008). Depression, parenting attributes, and social support among adolescent mothers attending a teen tot program. Journal of Pediatric and Adolescent Gynecology, 21(5), 275-281. doi: 10.1016/j.jpag.2008.02.002

Cutrona, C. E., \& Troutman, B. R. (1986). Social support, infant temperament, and parenting self-efficacy: A mediational model of postpartum depression. Child Development, 57(6), 1507-1518.

DeCastro, F., Hinojosa-Ayala, N., \& Hernandez-Prado, B. (2011). Risk and protective factors associated with postnatal depression in Mexican adolescents. Journal of Psychosomatic Obstetrics \& Gynecology, 32(4), 210-217. doi: $10.3109 / 0167482$ X.2011.626543

DeVito, J. (2007). Self-perceptions of parenting among adolescent mothers. The Journal of Perinatal Education, 16(1), 16-23. doi: 10.1624/105812407X170680

Farkas, C., \& Valdés, N. (2010). Maternal stress and perceptions of self-efficacy in socioeconomically disadvantaged mothers: An explicative model. Infant Behavior and Development, 33(4), 654-662. doi: 10.1016/j.infbeh.2010.09.001

Faul, F., Erdfelder, E., Buchner, A., \& Lang, A. G. (2009). Statistical power analyses using $\mathrm{G}^{*}$ Power 3.1: Tests for correlation and regression analyses. Behavior Research Methods, 41(4), 1149-1160. doi: 10.3758/BRM.41.4.1149

González-Forteza, C., Jiménez-Tapia, J. A., Ramos-Lira, L., \& Wagner, F. A. (2008). Aplicación de la Escala de Depresión del Center of Epidemiological Studies en adolescentes de la Ciudad de México. Salud Pública de México, 50(4), 292-299.
Gutiérrez, J. P., Rivera-Dommarco, J., Shamah-Levy, T., Villalpando-Hernández. S., Franco, A., Cuevas-Nasu, L., \& Hernández-Ávila, M. (2012). Encuesta Nacional de Salud y Nutrición 2012. Resultados Nacionales. Cuernavaca, México: Instituto Nacional de Salud Pública (MX). Retrieved from: http://ensanut.insp. $\mathrm{mx}$ /informes/ENSANUT2012ResultadosNacionales.pdf

Hastings, R. P., \& Brown, T. (2002). Behavior problems of children with autism, parental self-efficacy, and mental health. American Journal on Mental Retardation, 107(3), 222-232. doi: 10.1352/0895-8017(2002)107<0222:BPOCWA > 2.0.CO;2

Ibarra-Yruegas, B., Lara, M. A., Navarrete, L., Nieto, L., \& Kawas Valle, O. (2016). Psychomet-ric properties of the Postpartum Depression Predictors InventoryRevised for pregnant women in Mexico. Journal of Health Psychology. doi: $10.1177 / 1359105316658969$

Instituto Nacional de Estadística y Geografía, INEGI. (2015). Estadísticas A Propósito De Día Internacional De La Juventud. Retrieved from: http://www.inegi.org. $\mathrm{mx} /$ saladeprensa/aproposito/2015/juventud0.pdf

Kendall, S., \& Bloomfield, L. (2005). Developing and validating a tool to measure parenting self-efficacy. Journal of Advanced Nursing, 51(2), 174-181. doi: 10.1111/j.1365-2648.2005.03479.x

Knoche, L. L., Givens, J. E., \& Sheridan, S. M. (2007). Risk and protective factors for children of adolescents: Maternal depression and parental sense of competence. Journal of Child and Family Studies, 16(5), 684-695.

Lara, M. A., Navarro, C., \& Navarrete, L. (2010). Outcome results of a psycho-educational intervention in pregnancy to prevent PPD: A randomized control trial. Journal of Affective Disorders, 122(1), 109-117. doi: 10.1016/j.jad.2009.06.024

Lara, M. A., Berenzon, S., Juárez, F., Medina, M. E., Natera, G., Villatoro, J. A., \& Gutiérrez, M. L. (2012). Population study of depressive symptoms and risk factors in pregnant and parenting Mexican adolescents. Revista Panamericana de Salud Pública, 31(2), 102-108.

Lanzi, R. G., Bert, S. C., \& Jacobs, B. K. (2009). Depression among a sample of firsttime adolescent and adult mothers. Journal of Child and Adolescent Psychiatric Nursing, 22(4), 194-202. doi: 10.1111/j.1744-6171.2009.00199.x

Le, H. N., \& Lambert, S. F. (2008). Culture, context, and maternal self-efficacy in Latina Mothers. Applied Development Science, 12(4), 198-201. doi: $10.1080 / 10888690802388136$

Leahy-Warren, P., \& McCarthy, G. (2011). Maternal parental self-efficacy in the postpartum period. Midwifery, 27(6), 802-810. doi: 10.1016/j.midw.2010.07.008

Lipscomb, S. T., Leve, L. D., Harold, G. T., Neiderhiser, J. M., Shaw, D. S., Ge, X., \& Reiss, D. (2011). Trajectories of parenting and child negative emotionality during infancy and tod-dlerhood: a longitudinal analysis. Child Development, 82(5), 1661-1675. doi: 10.1111/j.1467-8624.2011.01639.x

Martínez, B. A., \& Quintino, P. F. (2016). Estudio del embarazo en adolescentes en el Distrito Federal, desde un enfoque de género, 2005-2014. México: Consejo de Evaluación del Desarrollo Social del Distrito Federal. Retrieved from: http:// data.evalua.cdmx.gob.mx/docs/gral/Informe $\% 20$ Estudio $\% 20 \mathrm{de} \% 20$ Embarazo\%20de\%20Adolescente.pdf

Navarro, C., Navarrete, L., \& Lara, M. A. (2011). Factores asociados a la percepción de eficacia materna durante el posparto. Salud Mental, 34(1), 37-43.

Panzarine, S., Slater, E., \& Sharps, P. (1995). Coping, social support, and depressive symptoms in adolescent mothers. Journal of Adolescent Health, 17(2), 113-119. doi: 10.1016/1054-139X(95)00064-Y

Pereira, P. K., Lovisi, G. M., Lima, L. A., Legay, L. F., deCintra, J. F., Santos, S. A., ... \& Valen-cia, E. (2011). Depression during pregnancy: Review of epidemiological and clinical aspects in developed and developing countries. In T. Uehara, Psychiatric Disorders-Trends and Developments (pp. 267-290). Retrieved from: https://cdn.intechopen.com/pdfs-wm/22665.pdf/

Radloff, L. S. (1977). The CES-D scale: A self-report depression scale for research in the general population. Applied Psychological Measurement, 1(3), 385-401.

Razurel, C., Kaiser, B., Antonietti, J. P., Epiney, M., \& Sellenet, C. (2017). Relationship between perceived perinatal stress and depressive symptoms, anxiety, and parental self-efficacy in primiparous mothers and the role of social support. Women \& Health, 57(2), 154-172.

Records, K., Rice, M., \& Beck, C. T. (2007). Psychometric assessment of the Postpartum Depression Predictors Inventory-Revised. Journal of Nursing Measurement, 15(3), 189-202.

Shapiro, J. R., \& Mangelsdorf, S. C. (1994). The determinants of parenting competence in adolescent mothers. Journal of Youth and Adolescence, 23(6), 621-641.

Teti, D. M., \& Gelfand, D. M. (1991). Behavioral competence among mothers of infants in the first year: The mediational role of maternal self-efficacy. Child Development, 62(5), 918-929. 